\title{
ANALYSIS OF COST VARIATION OF ANTI-CANCER DRUGS
}

\section{Prasan R. Bhandari}

Department of Pharmacology, SDM College of Medical Sciences \& Hospital, Dharwad, Karnataka

Article Info: Received 19 February 2018; Accepted 25 March. 2019

Cite this article as: Bhandari, P. (2019). ANALYSIS OF COST VARIATION OF ANTI-CANCER DRUGS. Journal of Biomedical and Pharmaceutical Research, 8(2).

DOI: https://doi.org/10.32553/jbpr.v8i2.582

Address for Correspondence: Prasan R. Bhandari, Department of Pharmacology, SDM College of Medical Sciences \& Hospital, Dharwad, Karnataka

Conflict of interest statement: No conflict of interest

\section{ABSTRACT:}

Introduction: Indian pharmaceutical industry being one of the largest pharmaceutical markets in the world has a large number of branded formulations and generic brands of the same drug with a large difference in their selling price. The study was planned to find out variation in cost of anti-cancer drugs

Methods: Information was sourced from NETMED MOBILE APP. The drug formulation being manufactured by only one company or being manufactured by different companies; however, in different strengths would be excluded. Difference in the maximum and minimum price of the same drug formulation manufactured by different pharmaceutical companies and percentage variation in price would be calculated.

Results: The maximum cost variation in the alkylating agents group was seen with Oxaliplatin $50 \mathrm{mg} / 10 \mathrm{ml}(71.43 \%)$. In the antimetabolite group the maximum cost variation was seen in Gemicitabine $1000 \mathrm{mg}$ (357.67\%). 68.7\% cost variation was observed with Paclitaxel $30 \mathrm{mg} / 5 \mathrm{ml}$ in the antimitotic natural products group. Doxorubicin $10 \mathrm{mg} / 5 \mathrm{ml}$ showed the maximum cost variation in the cytotoxic antibiotic group as well amongst all the anticancer drugs. Within the targeted group imatinib 400mg showed the maximum cost variation i.e $505.20 \%$.

Conclusion: Thus, this study highlights that there is a significant price difference among the anticancer drugs manufactured by different companies. Hence stringent measures should be brought into implementation by the government and concerned agencies for uniformity in drug pricing.

Keywords: Cost-Analysis, Anti-cancer; Analysis

\section{INTRODUCTION}

Cancer is a major health problem responsible for $9 \%$ of deaths worldwide. In developed countries like USA, $25 \%$ of deaths are related to some form of cancer [1], whereas in India there are 2-2.5 million cases of cancer at any point of time and 0.7 to 0.9 million new cases are being detected every year and approximately half of these cases die [2]. Like in any other country, cancer consumes a major portion of health budget in India also.

Generally, anti-cancer drugs are costlier than any other category of drugs and they substantially contribute to the growing drug expenditure by the patients [3]. There are many causes for the high cost of anti-cancer drugs like high cost of drug development [4], 
virtual monopoly [5], lack of reduction of cost even after generic versions are available [6], lack of threshold for clinical benefits [7], incentive for more chemotherapy [8] and also the sheer seriousness of the disease as many cancers except the early stage cancers, testicular cancer, and certain blood cancers, are incurable and patients willing to pay any amount of money to get the latest drugs [9].

In developed countries, where a system of medical insurance is in place, it may not be a concern but in developing countries like India, where the medical insurance is only in an emerging stage, affordability to anti-cancer drugs becomes a major concern [10]. The compliance of the patient also significantly depends on the cost of the prescribed medicines [11] and higher cost means a decreased compliance.

Pharmaceutical market in India has over 20,000 medicine formulations [12] and majority of them are sold under brand names [13]. Indian markets are flooded with a huge number of anti-cancer drugs and the same drugs are sold under different brands [14] which puts the prescribing physicians in a difficult state to choose the best drug for a given patient.

Information generated from cost analysis studies will be helpful both for the doctors in choosing the correct medicine for their patients and also for policy makers in successfully utilizing the meager resources that are available [15]. A comprehensive search in various databases and internet would be done for the study to analyze the variation of prices among anti-cancer drugs in the Indian market.

\section{MATERIALS AND METHODS}

1. Initially it was decided that the price in INR of anti-cancer drugs manufactured by different pharmaceutical companies in India, in the same strength would be obtained from "Current Index of Medical Specialties".
2. However, after scanning some similar literature it was observed that one of the major limitations of such studies was that, sources of information were limited to CIMS. But there are few other brands which are marketed in India but not published in the above-mentioned source.

3. Hence going by the explosion of online pharmacies it was decided to obtain the information from these sources. They would provide the current prices.

4. After scouting numerous online pharmacies and drug price webpages of India such as medguideindia, netpharmacy, 1mg.com, medicineindia, drug, drugtodayonlineindia.com, CIMS (online version); it was personally observed that the ease of obtaining the data was best with netmeds app. One could filter the prices of medicines as desired from low to high or vice versa. One could even remove the out of stock medicines.

5. Hence the information was sourced from NETMED MOBILE APP.

6. The drug formulation being manufactured by only one company or being manufactured by different companies; however, in different strengths would be excluded.

7. Cost of the anti-cancer drug formulation would be calculated for an average of 1 UNIT (tablets / CAPSULES).

8. Difference in the maximum and minimum price of the same drug formulation manufactured by different pharmaceutical companies and percentage variation in price would be calculated.

9. Percentage cost variation would be calculated as follows:

$\%$ Cost variation $=$ Maximum cost - Minimum $\underline{\text { cost } \times 100}$

Minimum cost

10. The cost ratio i.e. the ratio between the maximum and minimum cost of the same generic anti-cancer drug would be calculated as follows: 
Prasan R. Bhandari, Journal of Biomedical and Pharmaceutical Research

Cost ratio $=$ Maximum cost $/$ Minimum cost

\section{STATISTICAL ANALYSIS}

The findings of our observational study would be expressed as absolute numbers and percentages.

\section{RESULTS}

As seen in Table 1, Figure 1-3, the maximum cost variation in the alkylating agents group was seen with Oxaliplatin $50 \mathrm{mg} / 10 \mathrm{ml}$ (71.43\%).
In the antimetabolite group the maximum cost variation was seen in Gemicitabine $1000 \mathrm{mg}$ (357.67\%) table 1, Figure 4-5.

$68.7 \%$ cost variation was observed with Paclitaxel $30 \mathrm{mg} / 5 \mathrm{ml}$ in the antimitotic natural products group Table1 , Figure 6,7.

Doxorubicin $10 \mathrm{mg} / 5 \mathrm{ml}$ showed the maximum cost variation in the cytotoxic antibiotic group as well amongst all the anticancer drugs. Table 1, Figure 8,9.

Within the targeted group imatinib 400mg showed the maximum cost variation i.e 505.20\%.Table 1, Figure 10,11.

\section{TABLE 1: MAXIMUM PRICE, MINIMUM PRICE, COST RATIO'S AND COST VARIATION IN ANTICANCER DRUGS}

\begin{tabular}{|c|c|c|c|c|}
\hline DRUG & $\begin{array}{l}\text { MAXIMUM } \\
\text { PRICE INR }\end{array}$ & $\begin{array}{l}\text { MINIMUM } \\
\text { PRICE INR }\end{array}$ & $\begin{array}{l}\text { COST RATIO = } \\
\text { MAXIMUM } \\
\text { PRICE/MINIMU } \\
\text { M PRICE }\end{array}$ & $\begin{array}{l}\text { COST VARIATION } \\
=\quad \text { MAXIMUM } \\
\text { PRICE } \\
\text { MINIMUM } \\
\text { PRICE/MINIMU } \\
\text { M PRICE * } 100\end{array}$ \\
\hline \multicolumn{5}{|l|}{ ALKYLATING AGENTS } \\
\hline Cyclosporine $500 \mathrm{mg}$ & 76 & 75 & 1.01 & 1.33 \\
\hline $\begin{array}{l}\text { Ifosphamide } 2 \mathrm{gm}+\text { Mesna } \\
\text { 100mg }\end{array}$ & 1217 & 1017 & 1.20 & 19.67 \\
\hline Cisplatin $50 \mathrm{mg}$ & 350 & 316 & 1.11 & 10.76 \\
\hline Cisplatin $10 \mathrm{mg}$ & 89 & 63 & 1.41 & 41.27 \\
\hline Oxaliplatin $50 \mathrm{mg} / 10 \mathrm{ml}$ & 3312 & 1932 & 1.71 & 71.43 \\
\hline Oxaliplatin $100 \mathrm{mg} / 20 \mathrm{ml}$ & 6726 & 4800 & 1.40 & 40.13 \\
\hline Oxaliplatin $100 \mathrm{mg} / 50 \mathrm{ml}$ & 4300 & 3500 & 1.23 & 22.86 \\
\hline Carboplatin $450 \mathrm{mg} / 45 \mathrm{ml}$ & 2802 & 2222 & 1.26 & 26.10 \\
\hline \multicolumn{5}{|l|}{ ANTIMETABOLITES } \\
\hline Methotrexate $5 \mathrm{mg}$ & 82 & 33 & 2.48 & 148.48 \\
\hline Methotrexate $7.5 \mathrm{mg}$ & 114 & 44 & 2.59 & 159.09 \\
\hline Cytarabine $15 \mathrm{mg} / 10 \mathrm{ml}$ & 1241 & 1107 & 1.12 & 12.10 \\
\hline Gemicitabine $200 \mathrm{mg}$ & 1512 & 777 & 1.95 & 94.59 \\
\hline Gemicitabine 1000mg & 6920 & 1512 & 4.58 & 357.67 \\
\hline \multicolumn{5}{|l|}{$\begin{array}{ll}\text { ANTIMITOTIC } & \text { NATURAL } \\
\text { PRODUCTS } & \\
\end{array}$} \\
\hline Vincristine $1 \mathrm{mg} / \mathrm{ml}$ & 57 & 51 & 1.12 & 11.76 \\
\hline Vinorelbine $10 \mathrm{mg} / \mathrm{ml}$ & 3299 & 2700 & 1.22 & 22.19 \\
\hline Vinolelbine $50 \mathrm{mg} / 5 \mathrm{ml}$ & 16900 & 11700 & 1.44 & 44.44 \\
\hline
\end{tabular}


Prasan R. Bhandari, Journal of Biomedical and Pharmaceutical Research

\begin{tabular}{|l|l|l|l|l|}
\hline Paclitaxel 30mg/5 ml & 1746 & 1035 & 1.69 & 68.70 \\
\hline CYTOTOXIC ANTIBIOTICS & & & & \\
\hline Doxorubicin $10 \mathrm{mg} / 5 \mathrm{ml}$ & 4425 & 206 & 21.48 & 2048.06 \\
\hline Doxorubicin 20mg/10 ml & 49275 & 20490 & 2.40 & 140.48 \\
\hline Mitomycin 40mg/unit & 2620 & 2168 & 1.21 & 20.85 \\
\hline TARGETED AGENTS & & & & \\
\hline Imatinib 100 mg & 1015 & 413 & 2.46 & 145.76 \\
\hline Imatinib 400 mg & 3026 & 500 & 6.05 & 505.20 \\
\hline Geftinib 250 mg & 4402 & 1158 & 3.80 & 280.14 \\
\hline Sorafenib $20 \mathrm{mg}$ & 8880 & 1881 & 4.72 & 372.09 \\
\hline Rituximab $100 \mathrm{mg} / 10 \mathrm{ml}$ & 8500 & 5300 & 1.60 & 60.38 \\
\hline Rituximab $500 \mathrm{mg} / 50 \mathrm{ml}$ & 101110 & 30285 & 3.34 & 233.86 \\
\hline
\end{tabular}

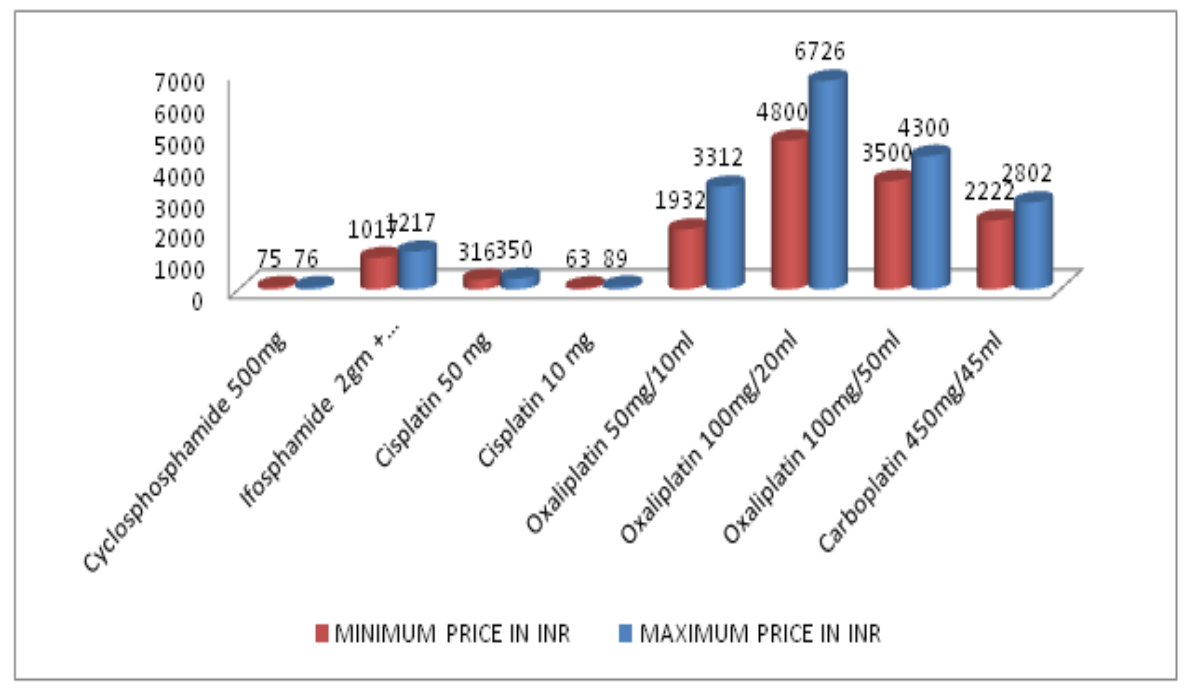

FIGURE 1: DIFFERENCE IN MAXIMUM AND MINIMUM PRICE OF ALKYLATING AGENTS

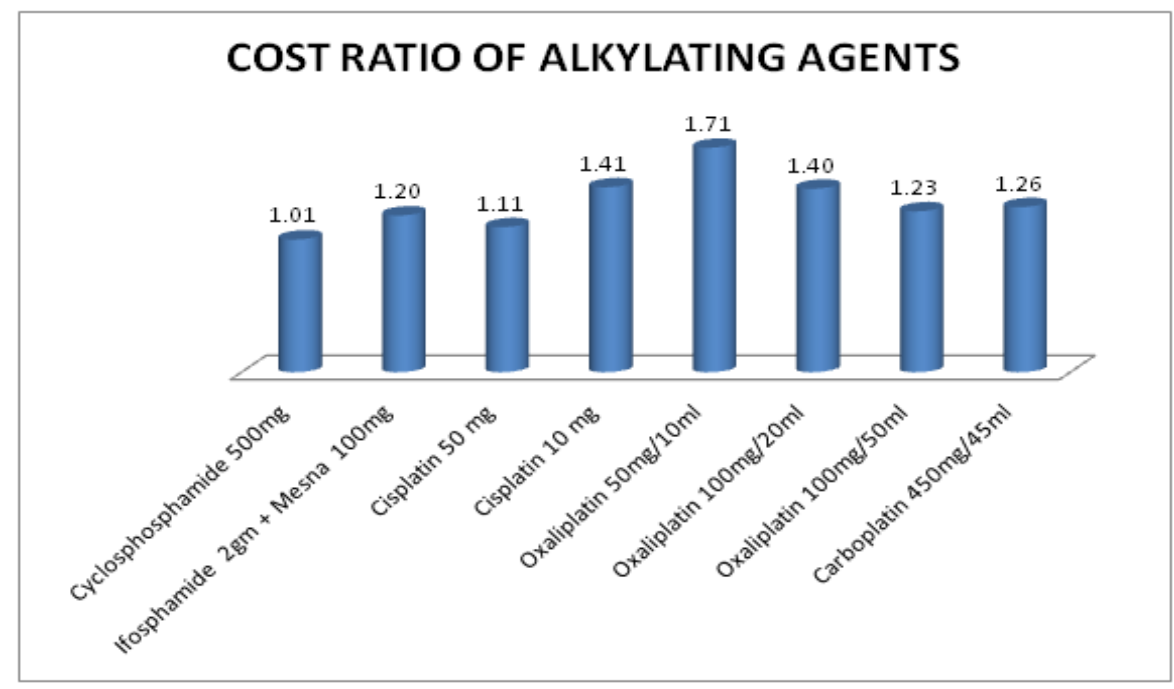

FIGURE 2: COST RATIO OF ALKYLATING AGENTS 
Prasan R. Bhandari, Journal of Biomedical and Pharmaceutical Research

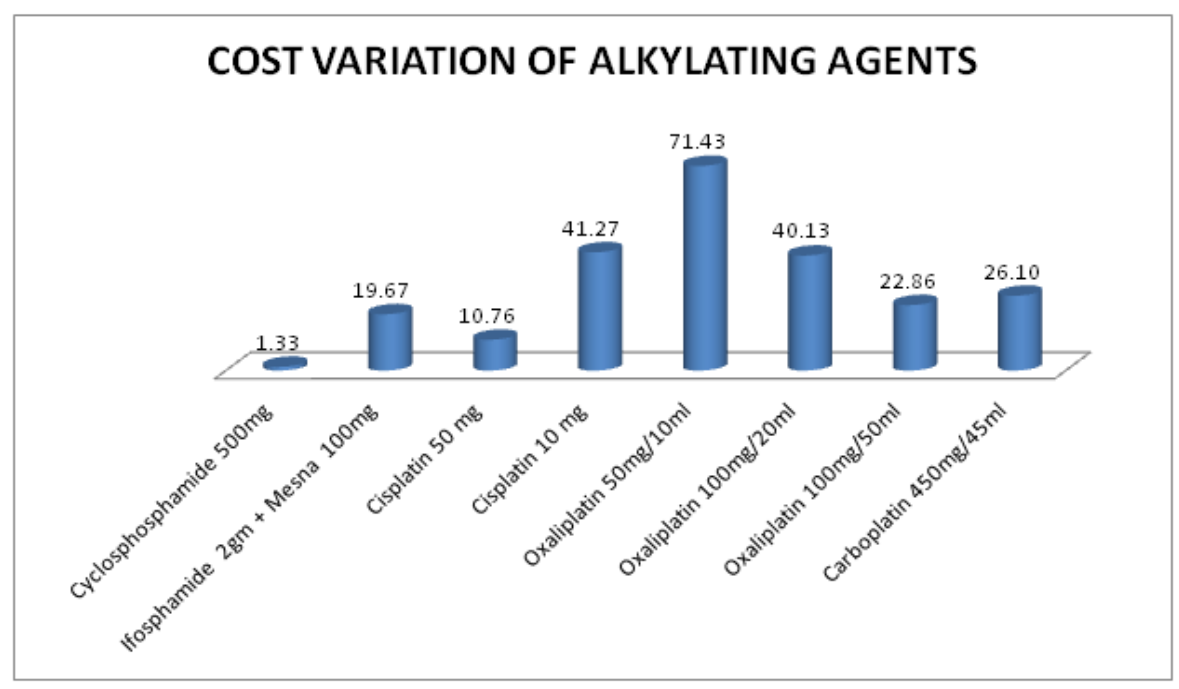

FIGURE 3: COST VARIATION OF ALKYLATING AGENTS

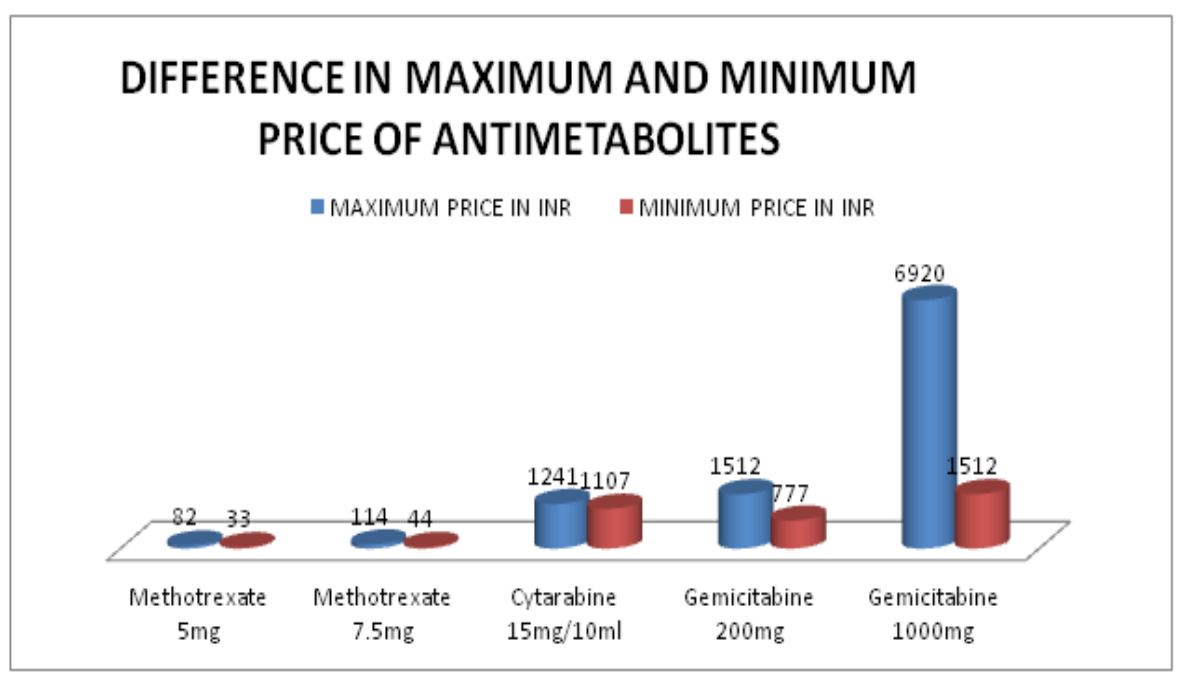

FIGURE 4: DIFFERENCE IN MAXIMUM AND MINIMUM PRICE OF ANTIMETABOLITES

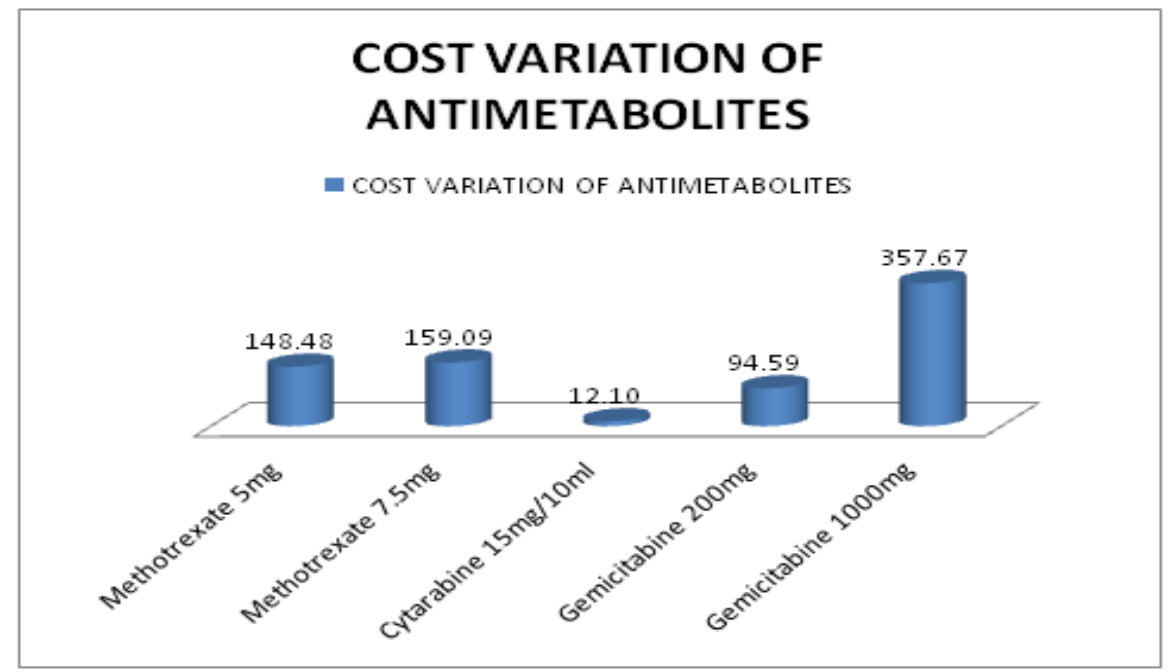

FIGURE 5: COST VARIATION OF ANTIMETABOLITES 
Prasan R. Bhandari, Journal of Biomedical and Pharmaceutical Research

\section{DIFFERENCE IN MAXIMUM AND MINIMUM PRICE OF ANTIMITOTIC NATURALPRODUCTS}

- MAXIMUM PRICE IN INR I MINIMUMM PRICE IN INR

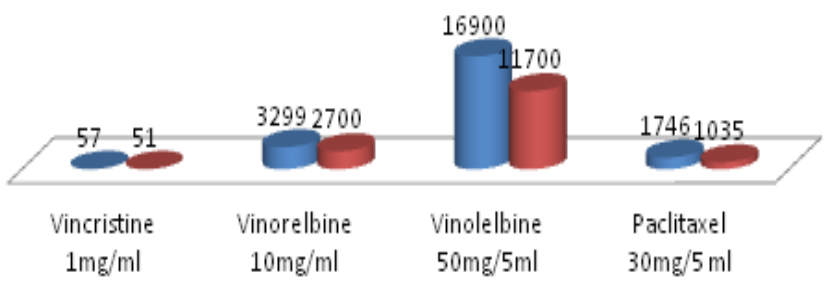

FIGURE 6: DIFFERENCE IN MAXIMUM AND MINIMUM PRICE OF ANTIMITOTIC NATURAL PRODUCTS

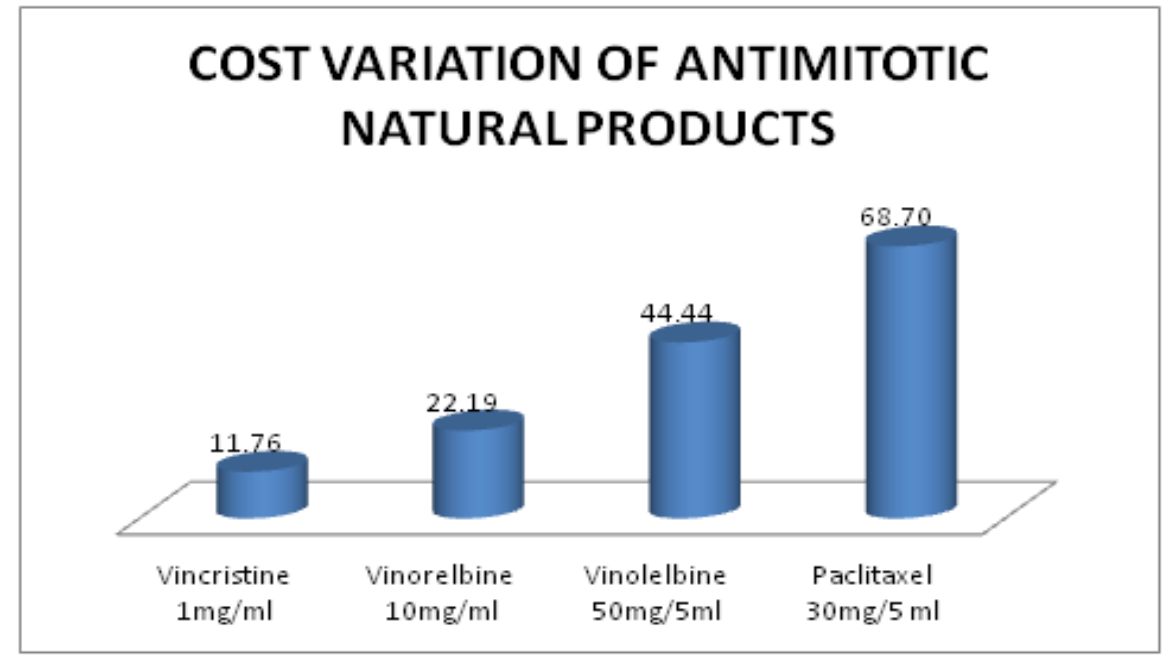

FIGURE 7: COST VARIATION OF ANTIMITOTIC NATURAL PRODUCTS

\section{DIFFERENCE IN MAXIMUM AND MINIMUM PRICE OF CYTOTOXIC ANTIBIOTICS}

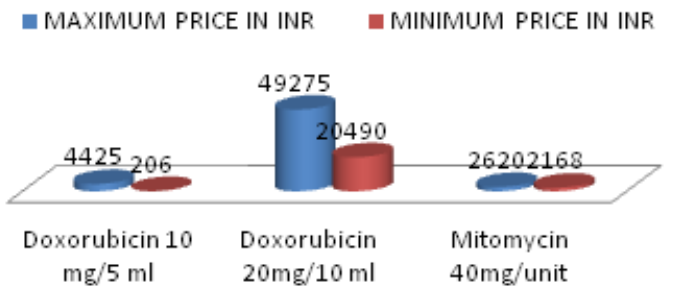

FIGURE 8: DIFFERENCE IN MAXIMUM AND MINIMUM PRICE OF CYTOTOXIC ANTIBIOTICS 
Prasan R. Bhandari, Journal of Biomedical and Pharmaceutical Research

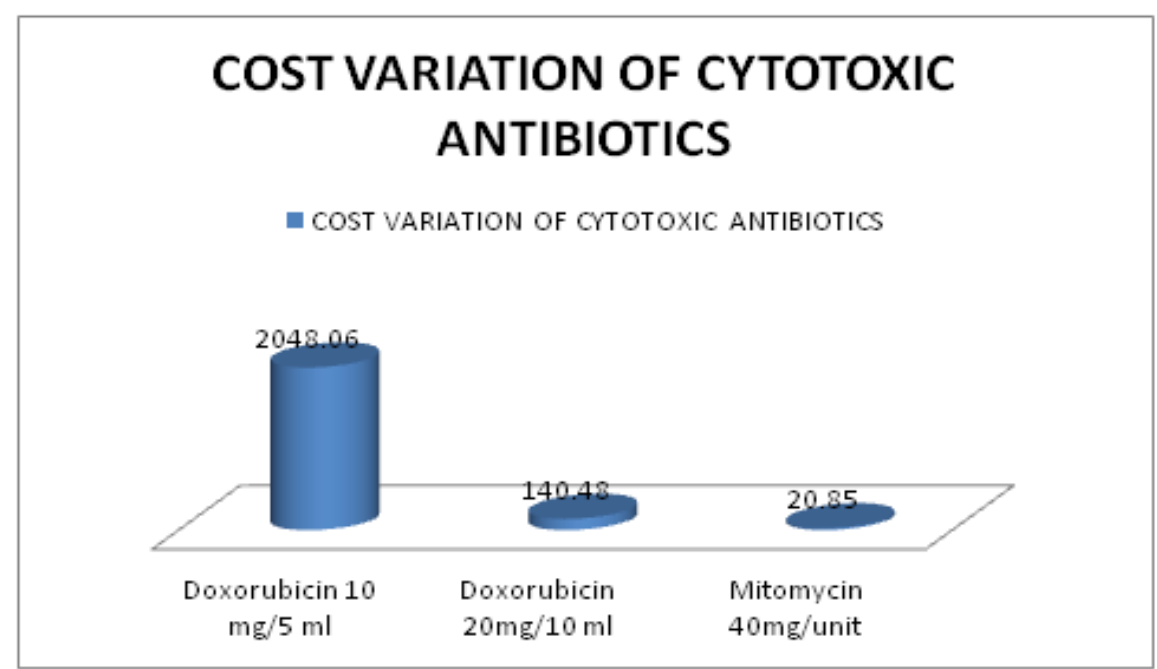

FIGURE 9: COST VARIATION IN CYTOTOXIC ANTIBIOTICS

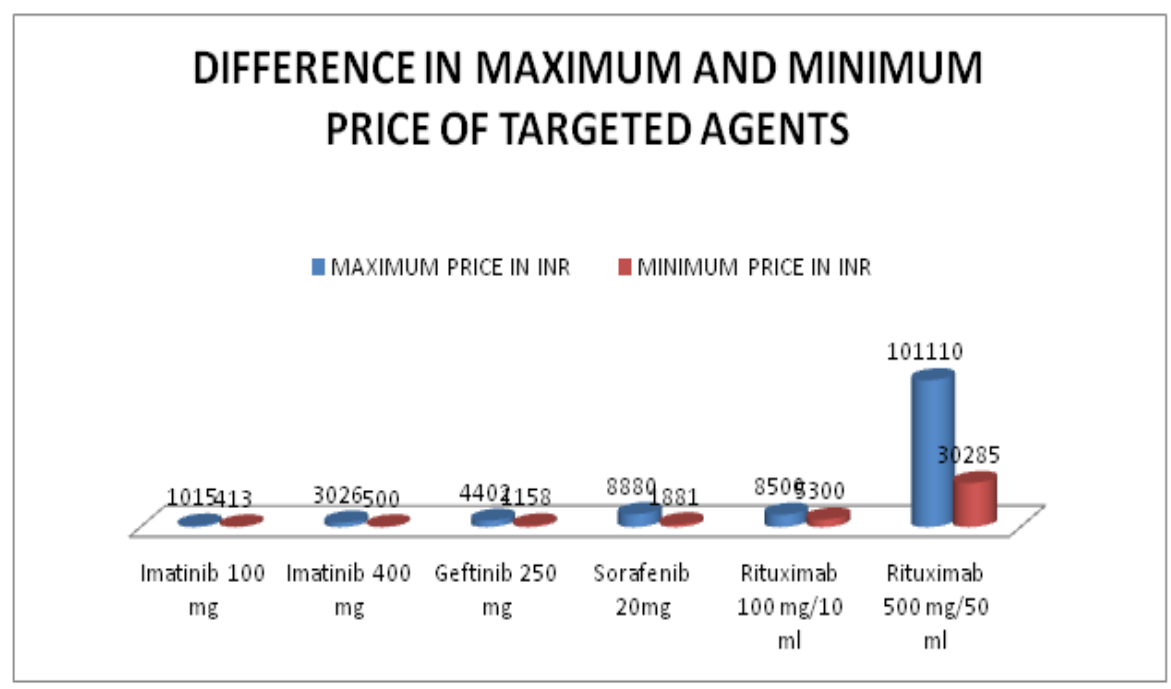

FIGURE 10: DIFFERENCE IN MAXIMUM AND MINIMUM PRICE OF TARGETED AGENTS

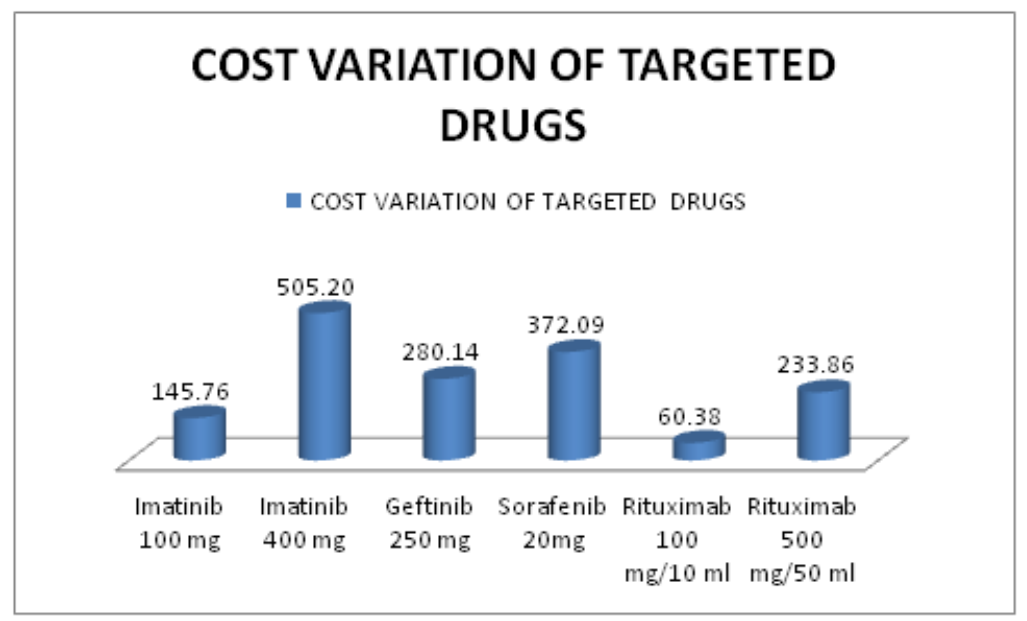

FIGURE 11: COST VARIATION OF TARGETED DRUGS 


\section{DISCUSSION}

The present study showed a very high variation in the maximum and minimum price of anticancer agents. The percentage variation in the cost was above $100 \%$ with most of the drugs and there is substantial variation in the cost of different brands of same anticancer agents in Indian market which is consistent with the results from previous studies.

Medication compliance is more important in such disorders and the cost of the prescribed drugs is one of the factors which decide drug compliance.[16,17]

Higher medication costs is one of the major reason for medication non-adherence which has been associated with adverse health outcomes such as treatment failure. This results in progression of the disorder thus enhances the medical care costs considerably. Prescribing physicians should pay attention to the drug prices in a country like India wherea huge percentage of patients are paying themselves for their medical bills and are not covered by insurance schemes.

Health insurance in India principally covers hospitalization and not out-patient or domiciliary care. Out-patient healthcare spending in India has augmented by almost fifty percent in the last 10 years. Hence there is an pressing need to create awareness to the health care providers about cost variation and its associated consequences.

It has been observed that doctors have suboptimal awareness of drug cost. In such situation if costly brands are prescribed patients has to pay unnecessarily more money and that creates an economic burden and can affect the compliance on the patient counterpart. The situation can be improved if drug cost is given greater emphasis during medical training program of doctors.

Presently, a limited number of drugs are under drug prices control order. Government should get higher number of drugs under price control. Drug Price Control Order (DPCO) and the National Pharmaceutical Pricing Authority (NPPA) are effective tools for regulation of drug prices. $[18,19]$

Even in economically strong counties like US, the issue of drug cost variation and high costs of anti-cancer drugs is extremely predominant. It was demonstrated that generic docetaxel had the lowest costs and cost/outcome however other drugs like abiraterone, enzalutamide and cabazitaxel were overpriced for their values. Siddique $M$ et al., suggested that high cost of generic cancer drugs also are the problems present in developed countries too. Mailankody $S$ et al., evaluated that price of cancer drugs is independent of novelty and current pricing models are not rational. Vogler $S$ et al., too mentions that the price of new cancer drugs varies widely from $28 \%$ to $388 \%$ between high-income countries. Interventions or changes in policies can help in lowering the cost of anti-cancer drug. These include breaking the monopoly in anti-cancer drug manufacturers, altering the regulatory guidelines by government agencies in favour of manufacturers with economical anti-cancer drugs and making the new anti-cancer drug approvals faster, increasing the cost effectiveness ratio of anti-cancer drugs. Additionally, achieving a balance between physician autonomy in prescribing anti-cancer drugs and costs incurred by patients too would benefit. Encourage non-profit generic companies by giving them tax incentives and other measures, value based reimbursement by medical insurance companies and bringing more anti-cancer drugs under DPCO. [20].

\section{CONCLUSION}

Thus, this study highlights that there is a significant price difference among the anticancer drugs manufactured by different companies. Hence stringent measures should be brought into implementation by the government and concerned agencies for uniformity in drug pricing. 
Self expenditure unfavorably disturbs the drug compliance in the long run. There must be a wide-ranging action from policymakers, regulatory authorities, government agencies, doctors, pharmacists, and the general public to solve this issue of cost variation of drug.

\section{REFERENCES}

1. Stone MJ, Aronoff BE, Evans WP, Fay JW, Lieberman ZH, Matthews CM, et al. History of the baylor Charles A. Sammons cancer center. Proc (Bayl Univ Med Cent) 2003;16:30-58.

2. Park K. In: Parks text book of preventive and social medicine. 20 th ed. Vol. 6. Jabalpur, MP, India: M/S Banarasi Das Bhanot Publishers; 2009. Epidemiology of chronic non-communicable diseases and conditions; pp. 332-35.

3. Suda KJ, Motl SE, Kuth JC. Inpatient oncology. Length of stay and hospital costs: Implications for rising inpatient expenditures. J Appl Res. 2006;6:127.

4. DiMasi JA, Grabowski HG. Economics of new oncology drug development. J Clin Oncol. 2007;25:209-16.

5. DiMasi JA, Feldman L, Seckler A, Wilson A. Trends in risks associated with new drug development: success rates for investigational drugs. Clinic Pharmacol Ther. 2010;87:272-77.

6. Karaca-Mandic $P$, McCullough JS, Siddiqui MA, Van Houten $H$, Shah ND. Impact of new drugs and biologics on colorectal cancer treatment and costs. J Oncol Pract. 2011;7:e30s-7s.

7. Jabbour E, Cortes JE, Kantarjian HM. Suboptimal response to or failure of imatinib treatment for chronic myeloid leukemia: what is the optimal strategy? Mayo Clin Proc. 2009;84:161-69.

8. Jacobson $M$, Earle $C C$, Price $M$, Newhouse JP. How Medicare's payment cuts for cancer chemotherapy drugs changed patterns of treatment. Health Aff (Millwood) 2010;29:1391-99.
9. Moreno-Aspitia A, Perez EA. Treatment options for breast cancer resistant to anthracycline and taxane. Mayo Clin Proc. 2009;84:533-45.

10. Meropol NJ, Schulman KA. Cost of cancer care: Issues and implications. J Clin Oncol. 2007;25:180-86.

11. Rao KS, Nundy M, Dua AS. Financing and Delivery of Health Care Services in India. New elhi: Ministry of Health \& Family Welfare, Government of India, Delivery of Health Services in the Private Sector; 2005. National Commission on Macroeconomics and Health; pp. 89-104.

12. Sakthivel S. National Commission on Macroeconomics and Health. New Delhi: Ministry of Health; 2005. Access to essential drugs and medicines. In: Lal PG (Ed.) pp. 185-210.

13. Jadhav NB, Bhosale MS, Adhav CV. Cost analysis study of antidiabetic drugs available in Indian market. Int J Med Res Health Sci. 2013;2:63-69.

14. Sundaram VM. Pharma industry in India. Drugs News Perspect. 2008;21:59-63.

15. Adam T, Evans DB, Murray CJL. Cost Effectiveness and Resource Allocation. 2003;1:3. Available from: http://www.resourceallocation.com/content/1/1/3.

16. Muir KW, Lee PP. Glaucoma Medication Adherence: Room for Improvement in Both Performance and Measurement. Arch Ophthalmol. 2011 Feb; 129:243-5.

17. Brown MT, Bussell JK. Medication Adherence: WHO Cares? Mayo Clin Proc. 2011 Apr; 86:304-14.

18. Chandrappa $S$, Rajarathna K. Cost variation analysis of various brands of topical eye preparations currently available in Indian pharmaceutical market. Int J Basic Clin Pharmacol 2018;7:2364-7.

19. Saiyadali A, Allisabanavar, Narayana Reddy S. Cost variation analysis of various brands of anti-epileptic drugs currently available in Indian pharmaceutical market. 
Prasan R. Bhandari, Journal of Biomedical and Pharmaceutical Research

International Journal of Basic \& Clinical Pharmacology. 2017;6:1666-69

20. Kolasani BP, Malathi DC, Ponnaluri RR. Variation of Cost among Anti-cancer Drugs
Available in Indian Market. J Clin Diagn Res. 2016;10:FC17-FC20. 